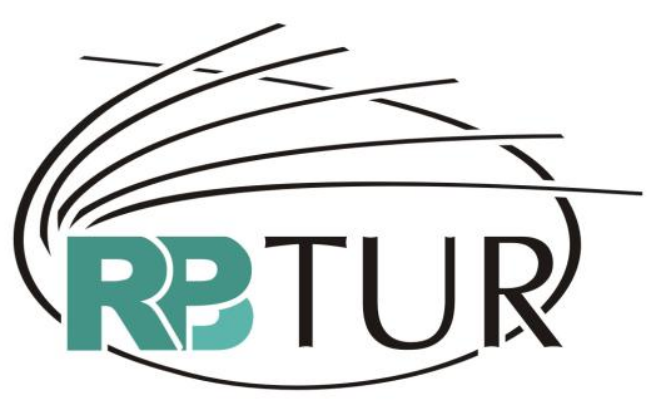

REVISTA BRASILEIRA DE PESQUISA EM TURISMO

\title{
A CONQUISTA DAS FÉRIAS: BREVE HISTÓRIA DO TURISMO NA ARGENTINA
}

\author{
ENJOYING HOLIDAYS: A SHORT STORY OF TOURISM IN \\ ARGENTINA
}

\section{LA CONQUISTA DE LAS VACACIONES: BREVE HISTORIA DEL TURISMO EL LA ARGENTINA}

Valéria Lima Guimarães ${ }^{1}$

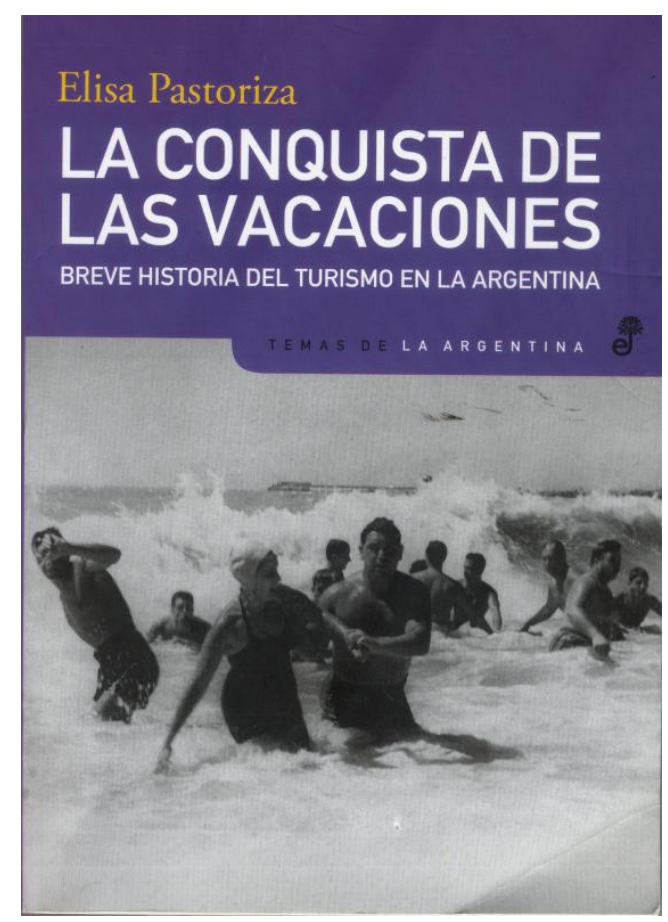

A história do turismo na Argentina começou a ser contada nos últimos anos. Autores como Regina Schütler, Noemi Wallingre, Melina Piglia, Rodolfo

${ }^{1}$ Professora do Departamento de Turismo da Universidade Federal Fluminense (UFF). Email: valeria@turismo.uff.br 
Bertoncello e Eliza Pastoriza vem produzindo um material de extrema relevância para a compreensão do fenômeno em terras portenhas, nos fornecendo subsídios para pensarmos suas conexões com outros países, especialmente o Brasil, o Uruguai, o Chile, os Estados Unidos da América e as nações da Europa Ocidental. Do lado brasileiro, Thiago Allis e Margarita Barretto, Raúl Burgos e David Frenkel foram alguns dos autores que se debruçaram sobre o estudo do turismo no país vizinho e examinaram suas conexões com o Brasil, acessando o passado histórico.

Nos dois países, como em tantos outros, a história do turismo fora sempre vista como um tema menor e desimportante e não atraía o interesse dos historiadores nem dos turismólogos e profissionais de áreas afins. Uma suspeita cronologia linear dos principais fatos relativos à institucionalização e normalização do turismo - que em alguns casos remontava à Antiguidade costumava ser o bastante para, de posse desses dados "históricos" acessórios, discutir outros temas considerados de maior relevância dentro do turismo. No campo da história, este sequer era notado.

Esse movimento de escrita de uma história do turismo, com as ferramentas próprias do historiador, resulta numa história problematizadora e crítica, com uso apurado das fontes, atenta às especificidades locais, às tensões e contradições do fenômeno turístico. Não há mais lugar para a reprodução do discurso turístico oficial ou dos folhetos comerciais como verdades históricas. Também está superado o pensamento linear acerca de uma harmoniosa evolução do turismo desde tempos remotos. Caminhamos ainda para a superação das crenças absolutas nos mitos fundadores do turismo, cujo maior exemplo é, sem dúvida, Thomas Cook.

Estrutura-se, então, nos últimos anos, um novo campo de investigação para a História e para o Turismo, debatido com profundidade em novas instituições voltadas para esse fim, como a International Comission for the History of Travel and Tourism - ICHTT, criada em 2001, com sede na Università della Svizzera Italiana, em Lugano. 
Novas e relevantes produções começam a chegar às prateleiras, como o trabalho de Sasha Pack, da Universidade de Buffalo, nos Estados Unidos, intitulado Tourism and Dictartorship: Europe's peaceful invasion of Franco's Spain, de 2006, lançado na Espanha em 2009, sob o título La invasión pacífica: los turistas y la España de Franco.

\section{La conquista de las vacaciones: breve historia del turismo en la}

Argentina é mais um desses belíssimos trabalhos que emergem no campo da história do turismo. Driblando a falta de interlocutores, por se tratar de tema pouco explorado e a dificuldade no acesso às fontes, a autora analisa primordialmente as transformações no turismo argentino, a partir da década de 1920, que possibilitaram paulatinamente o acesso das massas ao turismo, fenômeno definitivamente concretizado na década de 1960. A inclusão da Argentina na sociedade de consumo, sob influência do capitalismo americano e o advento das férias pagas, uma dura conquista estendida a amplos setores nos anos do primeiro peronismo (1946-1951), são o fio condutor da pesquisa. O principal cenário é o balneário de Mar del Plata, considerado pela autora um "exemplo paradigmático".

Numa análise densa, amparada em fontes diversas formadas por periódicos e documentos estatais, com uma meticulosa preocupação na sistematização e no tratamento dos dados, organizados em cuidadosos quadros e tabelas de autoria própria, Pastoriza aprofunda reflexões anteriores resultantes de quase duas décadas de pesquisa e publicadas em artigos científicos e livros, sendo o mais importante deles Las puertas al mar: consumo, ócio y política em Mar del Plata, Montevideo y Vina del Mar 2002, obra em que atua como editora e assina um capítulo.

A professora e diretora do Mestrado em História da Universidad Nacional de Mar del Plata examina minuciosamente as contradições e tensões nos projetos e práticas turísticos protagonizados pelas diferentes camadas sociais do país que, inevitavelmente, se esbarravam naquele balneário, especialmente na Praia Bristol, modernizada e urbanizada, levando a aristocracia a inventar novas espacialidades turísticas. Assim, eram inaugurados outros destinos 
turísticos exclusivos e elegantes onde se desenvolviam novas sociabilidades. A autora aponta, ao longo da década de 1930, a invenção da Praia Grande, também em Mar de Plata, como destino turístico, dos balneários de Vila Gesell, "o paraíso da juventude", celebrando as modas do culto ao corpo e dos esportes, e de Pinamar, na Província de Buenos Aires, além da longínqua e gélida Bariloche, com seu "PARNA" Nahuel Huapi (criado em 1934, cujo acesso, até mesmo para os mais ricos, era dificílimo). Assim, poderiam fugir do "excesso de urbanização" de Mar del Plata e fazer girar noutras paragens a roda do turismo de luxo.

Aos poucos, como conta Pastoriza, as camadas médias e também as populares, favorecidas ainda pelas políticas de turismo social, começaram a usufruir dos balneários, dos Parques Nacionais, criados ao longo das primeiras décadas do século $X X$, das serras, principalmente as de Córdoba, onde se situavam as mais importantes colônias de férias sindicais, as religiosas e, já no peronismo, as estatais. A força das campanhas do Touring e do Automóvel Clube argentinos no imaginário coletivo e a construção da red caminera, favoreceram amplamente o acesso das camadas médias aos destinos turísticos e implantaram em definitivo a cultura automobilista no país; os ferrocarris, que outrora tiveram importância primordial na formação de muitos destinos turísticos argentinos, como a própria Mar del Plata, por exemplo, começariam a perder prestígio.

Uma questão extremamente interessante apontada pela autora é a criação das colônias de férias e do turismo social antes mesmo do advento de Perón ao poder, em 1946. Ainda na década de 1930, por iniciativa dos governos conservadores e dos sindicatos, houve um amplo incentivo à criação e visitação aos Parques Nacionais, que faziam parte da estratégia de consolidação das fronteiras e construção da identidade nacional argentina. Sob o slogan "conhecer a pátria é um dever", viajar pelos lugares mais remotos, constatar a diversidade natural e cultural do país e, sobretudo, cultivar o sentimento de pertencimento, era um exercício de civismo, que deveria estar 
ao alcance de todos os cidadãos, evidenciando a inspiração nos governos europeus de matriz autoritária então em voga.

Entretanto, o peronismo reivindicou para si essas invenções como parte da política justicialista que visava à inclusão social dos trabalhadores. No turismo, a estatização de hotéis, de pousadas, dos ferrocarris, o aumento da oferta de colônias de férias (então a cargo da Fundação Eva Perón) e o barateamento dos pacotes turísticos - "você paga a viagem e o governo a hospedagem" - foram a tônica da política peronista e tiveram grande importância, conforme avalia a autora, como experimento para a condução das demais políticas sociais.

Sem se deixar influenciar pela sedutora retórica dos discursos presentes nas fontes, que em muitos casos universalizam o acesso ao turismo às camadas populares, a apoteose do livro é a percepção da autora de que, apesar de amplamente difundido no imaginário popular pelo peronismo, 0 desejo de viajar nas férias para os destinos turísticos argentinos, àquela altura já dotados de grande infra-estrutura, foi realizado de fato pelas camadas médias, que tinham mais condições de fazê-lo. Isso não refuta, conforme o raciocínio da autora, a constatação de que também, mas em menor proporção, muitos operários tivessem conseguido usufruir daquilo que muito cedo se colocou como uma nova necessidade da jovem nação argentina: o turismo de lazer.

\section{La conquista de las vacaciones: breve historia del turismo en la} argentina é uma obra imperdível, dessas que estimulam os pesquisadores brasileiros a atentar para a importância da história do turismo e a enfrentar com coragem, como fez a autora em seus país, nossos difíceis caminhos de pesquisa, sobretudo na busca e interpretação das fontes. 